\title{
Impacto de la concentración parcelaria en el paisaje de un municipio del sur de Salamanca, en una zona de espacios naturales protegidos
}

\section{Impact of the concentration of land holdings on the soil and landscape of a village in the South of Salamanca in a protected natural area}

\author{
María del Pilar García Rodríguez* y José Antonio García Rodríguez **
}

\section{INTRODUCCIÓN}

La concentración parcelaria es un proceso técnico y administrativo que intenta mejorar la explotación agraria del territorio mediante la creación de unidades de mayor superficie a partir de parcelas dispersas pertenecientes al mismo o los mismos propietarios. Con diversos antecedentes, este proceso se empezó a aplicar de manera masiva en España a partir de los años cincuenta y sesenta del pasado siglo. Lógicamente las áreas más afectadas fueron, en principio, las de mayor productividad agrícola, pero poco a poco se fueron incorporando a los planes de concentración territorios más marginales. Entre ellos están los de las orlas montañosas del Sur de la cuenca del Duero en la comunidad autónoma de Castilla y León. Como en otras áreas marginales del oeste de la Península Ibérica, y por una tradición cultural y jurídica de herencias muy distinta a la de regiones al norte o nordeste de España, estas zonas se han caracterizado históricamente por una subdivisión extrema de la propiedad de la tierra. Esto ha

\footnotetext{
* Departamento de Análisis Geográfico Regional y Geografía Física, Facultad de Geografía e Historia, Universidad Complutense de Madrid. España (mpgarcia@ghis.ucm.es).

** Departamento de Biología Animal, Parasitología, Ecología, Edafología y Química Agrícola, Facultad de Biología, Universidad de Salamanca. España (jantecol@usal.es).
} 
traído consigo a lo largo del tiempo una organización minifundista de la explotación del medio en la que cada propietario tenía dividida su propiedad en numerosas parcelas de exiguo tamaño y generalmente distantes unas de otras. El régimen de explotación fue de autosubsistencia hasta la década de los sesenta del siglo xx cuando se consolidó el éxodo masivo de los habitantes hacia las zonas urbanas. Ello trajo consigo el abandono o la marginalización de la explotación de gran parte de las superficies cultivadas hasta entonces, especialmente, dentro de los términos municipales, las más alejadas de los núcleos de población. Muchas veces estas parcelas han sido heredadas por los descendientes de los propietarios que ya han nacido fuera del entorno rural y ya no están interesados en explotarlas directamente. Además, el abandono del uso ha traído consigo un efecto de recuperación ambiental espontánea a través del proceso de la sucesión ecológica, cuyo resultado ha sido la recuperación de bosques y ecosistemas naturales en los antiguos predios agrícolas. Este paisaje adquiere un nuevo valor a medida que la Sociedad demanda naturaleza y conservación de la biodiversidad.

En consecuencia, el proceso de concentración parcelaria - que no olvidemos, se realiza con una importante aportación de fondos públicos- ha llegado digamos que históricamente tarde a determinadas zonas marginales, en el momento en el que la vocación del territorio ha pasado de agrícola a forestal y de conservación. No obstante, todavía es, en general, bienvenido por los habitantes y propietarios. Los que aún permanecen en los pueblos, porque ven facilitada la explotación, en general ganadera, en parcelas más manejables. Los propietarios ausentes, que son mayoría, porque unifican fincas muchas veces desconocidas para ellos en una o dos parcelas que pueden alquilar para su explotación a los residentes que aún se dedican al sector primario.

En todo caso, conviene evaluar si el balance de las ventajas administrativas es positivo frente a los costes de inversión pública y, sobre todo, ambientales, en determinadas zonas de elevado valor natural. Por ello conviene analizar y aportar datos sobre las consecuencias de las concentraciones parcelarias en los diferentes elementos del ecosistema (suelos, vegetación y fauna) así como en el paisaje de áreas en los que el capital de conservación puede ser un buen incentivo económico en las décadas que se avecinan.

El objetivo del trabajo es analizar el impacto que la concentración parcelaria ha provocado en el paisaje del municipio de Escurial de la Sierra situado en el sur de la provincia de Salamanca (España), caracterizado por suelos poco evolucionados y con un espesor muy pequeño, pero con valores florísticos, faunísticos y paisajísticos muy importantes.

Otros municipios próximos, con paisaje similar, están iniciando en la actualidad el proceso de concentración. Si las administraciones públicas toman 
conciencia del impacto que este proceso ha tenido en algunos pueblos, pueden intentar minimizar sus consecuencias en otras áreas con similares valores ecológicos. Un municipio colindante con el estudiado, Navarredonda de la Rinconada, incluido también en la Reserva de la Biosfera de las Sierras de Francia y Béjar ha comenzado el proceso de concentración parcelaria. En el verano de 2010 han quedado expuestos los mapas con las diferentes parcelas y con el trazado de los caminos de concentración. El conocimiento del impacto ambiental sufrido en Escurial de la Sierra unido a la lentitud del proceso debido al freno que impone la actual crisis económica, puede permitirles estar aún a tiempo de reducir el impacto en su territorio.

\section{ÁREA DE ESTUDIO}

El área de estudio (figura 1) se localiza en el sur de la provincia de Salamanca, centro-oeste de España, en una zona ecotónica de transición entre los

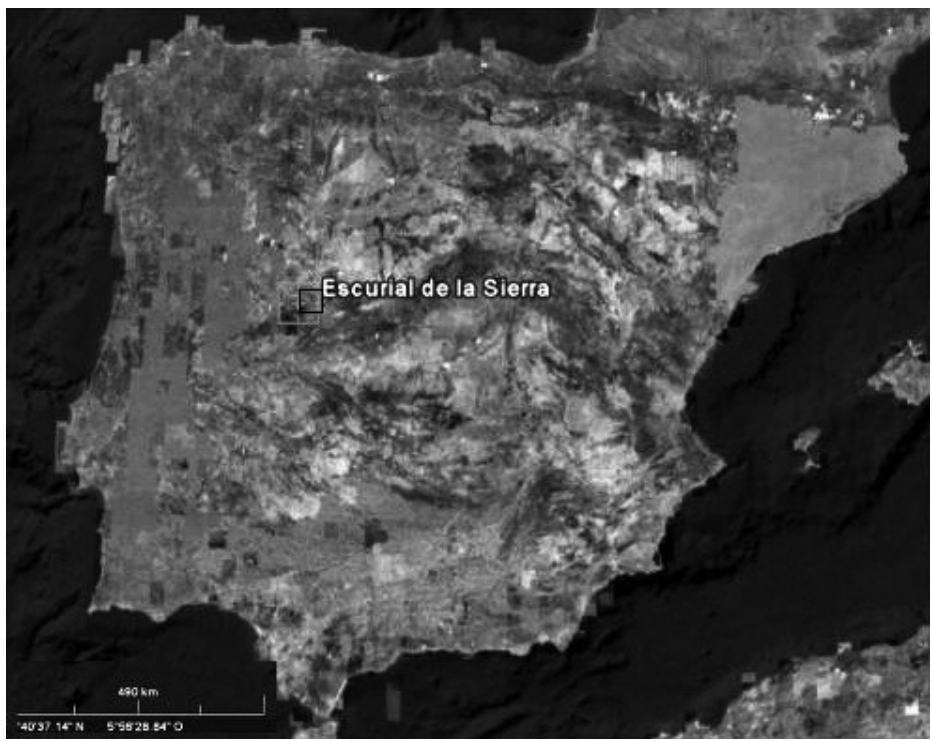

Fuente: http://earth.google.es 
paisajes adehesados de la penillanura y los bosques de media montaña mediterráneo-atlántica de las serranías occidentales del Sistema Central, en concreto de la Sierra de Francia. Es una zona con especiales valores naturales, perteneciendo todo el término de Escurial a la Reserva de la Biosfera de las Sierras de Francia y Béjar (UNESCO, 2006), y su extremo Sur al LIC (Lugar de Interés Comunitario de la Unión Europea) y ZEPA (Zona de Especial Protección para las Aves) de Quilamas, incluida, asimismo, en la REN (Red de Espacios Naturales Protegidos de la Junta de Castilla y León).

Escurial de la Sierra tiene una superficie de $20,97 \mathrm{~km}^{2}$ y está situado a una altitud entre 920 y $1.290 \mathrm{~m}$ en la vertiente Norte del cordal de la Sierra de Linares-Tamames, en la transición entre las comarcas del Campo Charro y la Sierra de Francia.

La geología del sector estudiado se caracteriza por la presencia de materiales muy homogéneos, pizarras del complejo esquisto-grauváquico de la formación Aldeatejada en la parte Norte del término municipal y materiales paleozoicos (Cámbrico, Ordovícico, Silúrico) ya en la Sierra, situada al Sur de la localidad. El clima es supramediterráneo subhúmedo con influencia atlántica, determinado por unas precipitaciones promedio de $800-1.000 \mathrm{~mm}$ y una temperatura media de $13{ }^{\circ} \mathrm{C}$. El municipio se sitúa entre dos cuencas hidrográficas: la mayor parte de él está atravesada por el río Huebra, perteneciente a la cuenca del Duero, aunque al sureste corresponde a la cuenca del Tajo, con pequeños arroyos que desembocan en el río Alagón (García Rodríguez, Puerto y Rodríguez, 1984). Los suelos están poco desarrollados, con la presencia de leptosoles, umbrisoles y cambisoles (WRBSR, 2007). Son suelos ligeramente ácidos, con pH entre 6 y 7 , con contenido medio en materia orgánica y nitrógeno, pobres en fósforo, potasio y calcio y textura franco arcillosa o franco arenosa. Se han clasificado como cambisoles húmicos y dístricos en el mapa de la provincia de Salamanca de 1977 (García, Forteza y Lorenzo, 1977), por lo que en la actualidad se pueden considerar, según clasificación de WRBSR-FAO de 2007 como umbrisoles y cambisoles. También aparecen leptosoles (Forteza et al., 1987). En todo caso son suelos con un factor limitante marcado por su poco espesor, apareciendo la roca madre muchas veces en superficie, como afloramientos rocosos que llegan a limitar su uso para cultivos.

La vegetación potencial pertenece a la serie marcescente-caducifolia del roble melojo (Quercus pyrenaica Willd.) (Rivas Martínez, 1987) al que probablemente alude el origen del topónimo, aunque los usos seculares de sus habitantes propiciaron la entrada del componente esclerófilo de la ecotonía: la encina (Quercus ilex subsp. Ballota (Desf.) Samp.) en forma de grandes ejem- 
plares, cuidadosamente manejados, que forman el vuelo poco denso de parte de los pastos comunales y de las, hasta ahora, pequeñas parcelas privadas que se roturaron para el cultivo del cereal, sustituido en parte durante las décadas de los sesenta y setenta del siglo xx, por el cultivo del fresón de secano. El uso de suelo estaba dedicado, pues, a pastos y pequeñas parcelas de cultivo en un régimen de autosubsistencia, completado por el cultivo de regadío en pequeñas propiedades familiares en los márgenes de los arroyos temporales y por el antiguo cultivo de castaños, hoy naturalizados en algunos enclaves del municipio (García-Rodríguez, 1991). Desde los años sesenta del siglo xx se produjo un abandono, primero paulatino pero desde los ochenta casi total, de los usos agrícolas y un cambio profundo de los usos ganaderos, con la pérdida total de la cabaña caprina, lo que ha supuesto una indudable mejora en la recuperación forestal y de los valores naturales, y el incremento de la bovina auspiciado por las actuales ayudas de la PAC (Política Agraria Comunitaria), llegando hasta niveles algo preocupantes de sobreexplotación que, en la actualidad, podrían comprometer de nuevo la recuperación forestal en zonas de pastos comunales (García-Rodríguez, 2004).

Dado que la potencialidad agraria de los suelos es ínfima y que, en consecuencia, el cultivo ha sido abandonado desde hace décadas en paralelo al desarrollo del país, el único interés socioeconómico del proceso de concentración parcelaria llevado a cabo, es el de aclarar la propiedad de la tierra hasta ahora subdividida en infinidad de parcelas no colindantes, y el de propiciar parcelas, que aún siendo todavía de muy escasa extensión (un promedio algo inferior a las dos hectáreas), permitirán su uso, generalmente en régimen de arrendamiento, para una ganadería vacuna en la actualidad y, de momento, sobredimensionada por las subvenciones europeas, o también para el ganado porcino autóctono para cuyos productos hay una demanda comercial en incremento.

\section{MATERIAL Y MÉTODOS}

Se han utilizado imágenes de los sensores TM y ETM+ de los satélites Landsat 5 y Landsat 7 de fechas 2 de agosto de 1987 y 10 de abril de 2001 respectivamente y del satélite Aster de la serie Terra del 2 de junio de 2006. Las imágenes de los satélites Landsat son anteriores al proceso de concentración y la imagen del satélite Aster es inmediatamente posterior a la realización de los caminos construidos para acceder a las nuevas parcelas. También se han utilizado imágenes Landsat obtenidas en Google Earth del año 2007 y fotografías 
aéreas. Todas las imágenes están georreferenciadas a coordenadas UTM y se han sometido a distintas mejoras espaciales, espectrales y radiométricas mediante el programa ERDAS Imagine 9.1. Entre estas mejoras destaca la obtención del Índice Normalizado de la Diferencia de Vegetación (NDVI) que relaciona los canales visibles e infrarrojos próximos mediante el algoritmo (IR-R)/(IR+R). En una tabla se han resumido los valores del NDVI para las clases más representativas. Asimismo otra tabla resume los valores digitales para todas las bandas de los satélites Landsat, salvo la banda térmica, y para las tres primeras bandas del satélite Aster.

En todas las imágenes seleccionadas se han efectuado distintos tratamientos espectrales con el fin de obtener aquellas combinaciones que permitan una mejor visualización de los impactos de la concentración. Entre las diferentes mezclas de canales espectrales se han escogido las combinaciones de bandas 4,3,2 de los satélites Landsat 5 y 7 (figuras 2 y 3 respectivamente) y 2,1,3 del satélite Aster (figura 4), ya que comparándolas, se ven claramente los cambios acaecidos a través de los últimos veinte años.

\section{RESULTADOS Y DISCUSIÓN}

La concentración parcelaria ha tenido lugar en los primeros años del siglo xxi. La superficie aportada para la concentración ha sido de 1067,0029 hectáreas, con una superficie atribuida de 1031,5585 hectáreas. El número de parcelas era de 10.375 correspondientes a 482 propietarios, con una media por propietario de 21,52 parcelas. Una vez efectuada la concentración el número de fincas es de 823 con una media de 1,707 por propietario. La superficie media de las parcelas antes de la concentración era de 0,1028 hectáreas y después 1,2534 hectáreas, con un índice de reducción de 12,60 y un coeficiente de concentración de 96,55 (datos de la Secretaría del Municipio de Escurial de la Sierra, 2005).

De estos datos se deduce el pequeño tamaño de las parcelas, incluso después del proceso de concentración. Esto ha obligado a la construcción de numerosos caminos, dado el elevado número de parcelas y propietarios, para acceder a las fincas. La construcción de estos caminos se inició en 2004 y concluyó a principios de 2006, originando un importante impacto ambiental. El objetivo del estudio es, pues, analizar este impacto en el paisaje del municipio. Para ello se comparan datos obtenidos por satélites de recursos naturales en años anteriores (1987 y 2001) y en una fecha inmediatamente posterior (junio de 2006) a la concentración parcelaria. 
FIGURA 2

IMAGEN TM 2-08-1987, 4-3-2 (R-V-A)

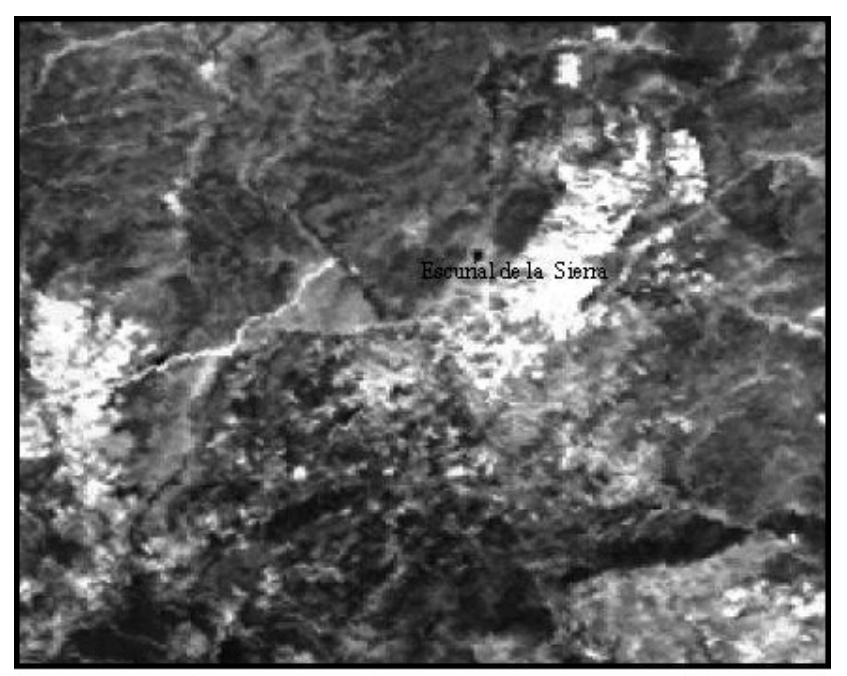

$\overbrace{0} \overbrace{2} \mathrm{~km}$

FIGURA 3

IMAGEN ETM 10-4-2001, 4-3-2 (R-V-A)

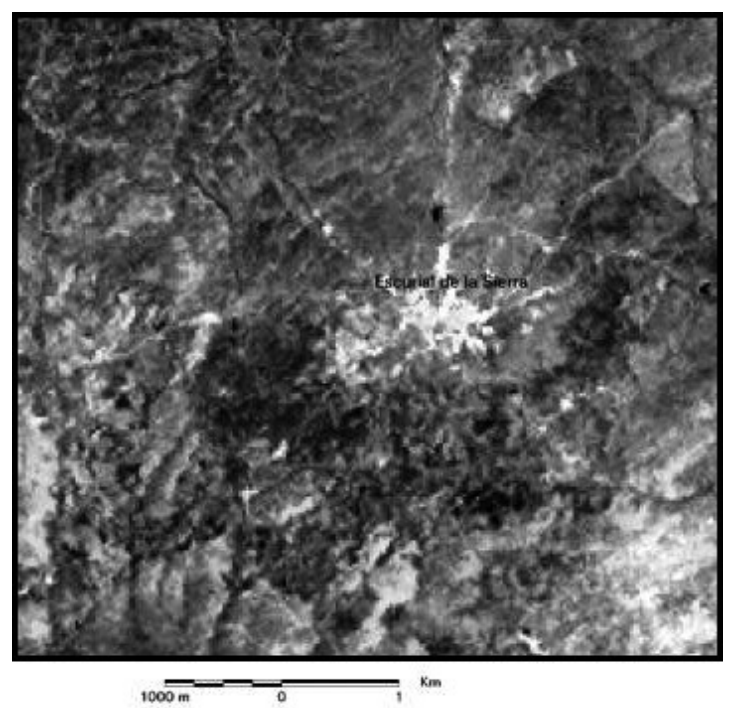

Estudios Geográficos, Vol. LXXII, 271, pp. 421-436, julio-diciembre 2011 ISSN: 0014-1496, eISSN: 1988-8546, doi: 10.3989/estgeogr.201116 
IMAGEN ASTER, 2-06-2006, 3-2-1 (R-V-A)

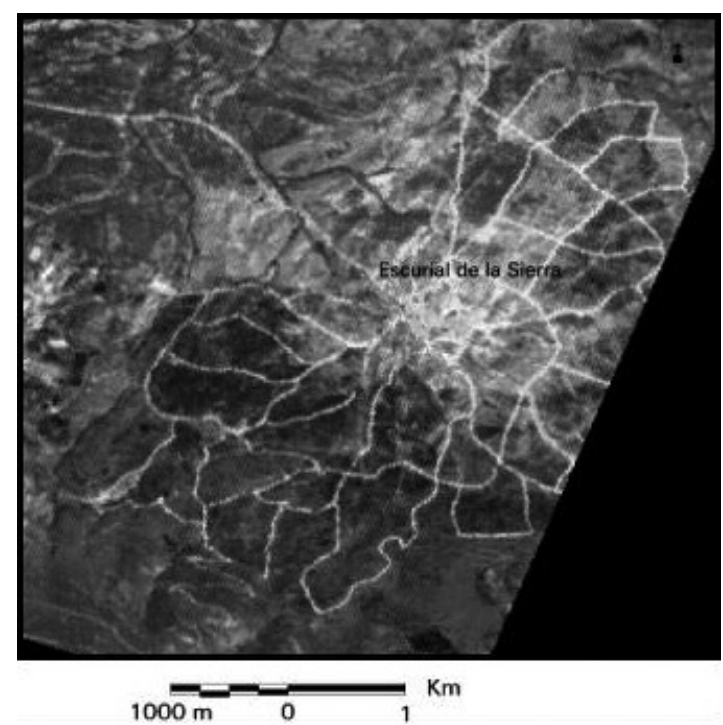

Las imágenes de satélite permiten comparar el paisaje de antes y después de la concentración. El gran impacto visual directo sobre el paisaje resulta evidente (comparar figuras 2 y 3 con figura 4). Se ha cambiado la fisonomía y el componente de calidad visual del paisaje de todo el territorio estudiado. Aunque en términos puramente cuantitativos, las hectáreas de bosques y matorrales convertidas en viales son aproximadamente 60 (un 2,5\% del territorio completo del término municipal), el impacto sobre la calidad ambiental paisajística es desproporcionado, al tratarse de estructuras lineales que atraviesan todos los ecosistemas del territorio en una malla densa como puede apreciarse en las imágenes.

En las imágenes TM y ETM de los satélites Landsat (figuras 2 y 3 respectivamente) apenas se aprecian caminos, mientras que la imagen Aster (figura 4) muestra un gran entramado de caminos en tonos claros. Este cambio se observa también en la imagen que se obtiene superponiendo las escenas de dos fechas (imagen Aster y ETM) y calculando la diferencia de valores digitales: en ella resaltan nítidamente los nuevos caminos en color muy claro (figura 5).

Mayor información ofrece la imagen resultante del Indice Normalizado de la Diferencia de Vegetación (NDVI) (figuras 6 y 7): esta combinación espectral 


\section{FIGURA 5}

DIFERENCIA ENTRE IMÁGENES ETM Y ASTER. EN BLANCO LOS CAMINOS CONSTRUIDOS DESPUÉS DE LA CONCENTRACIÓN PARCELARIA

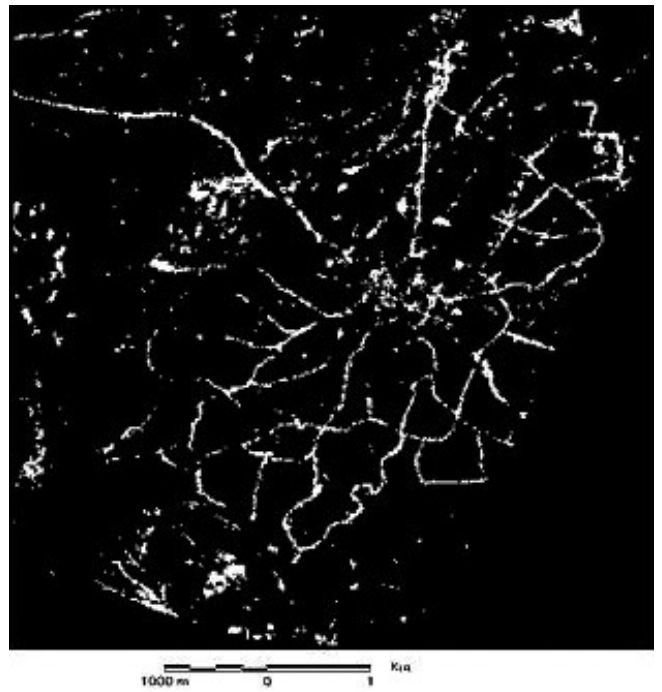

FIGURA 6

NDVI, ETM 10-4-2001

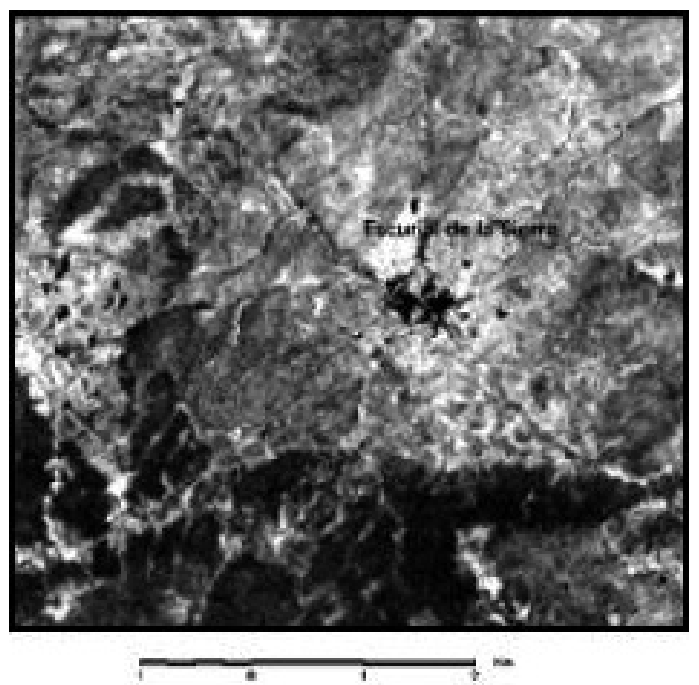

Estudios Geográficos, Vol. LXXII, 271, pp. 421-436, julio-diciembre 2011 ISSN: 0014-1496, eISSN: 1988-8546, doi: 10.3989/estgeogr.201116 
FIGURA 7

NDVI, ASTER 2-06-2006

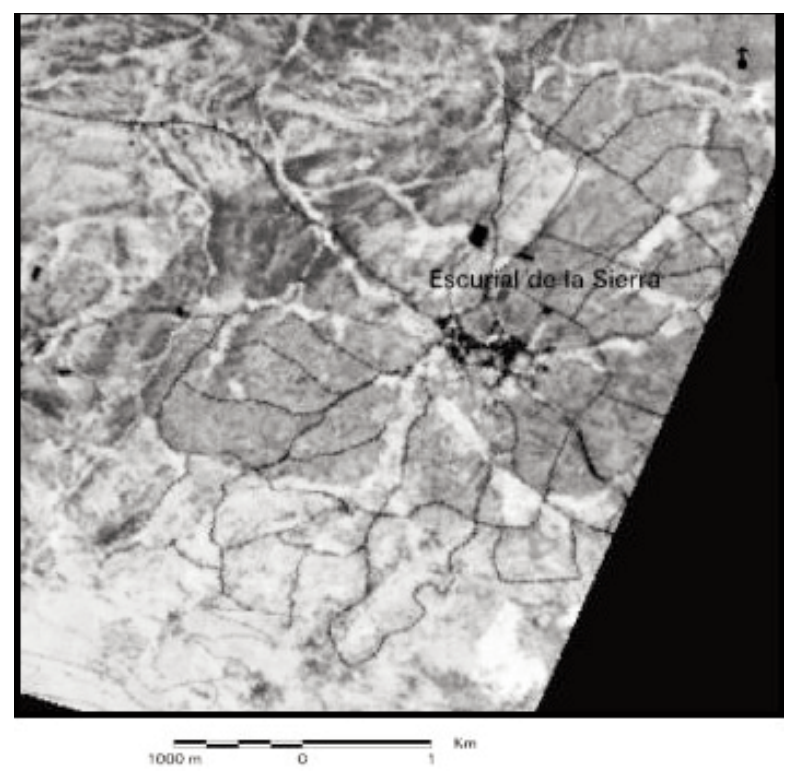

es la que muestra una mayor discriminación ya que resalta en colores muy claros las áreas con vegetación y, en negro, aquellas en las que ésta ha desaparecido completamente. En la imagen del NDVI del satélite ETM apenas se aprecia la existencia de caminos en colores oscuros, aún cuando al ser una imagen de primavera gran parte del territorio tiene colores muy claros debido a la alta actividad clorofílica. Por el contrario en la imagen del satélite Aster se pueden observar los caminos en tonos muy oscuros e incluso se ve que el impacto de los caminos es mayor que el de la carretera comarcal que une Escurial de la Sierra con municipios próximos.

El análisis de los valores digitales (ND) de las bandas de los distintos satélites permite establecer también diferencias entre los valores de cada muestra en las diferentes fechas analizadas (tabla 1). En la imagen del satélite Aster los caminos realizados para la concentración tienen valores digitales más altos en las bandas 1 y 2 que las áreas con vegetación y no muestra grandes diferencias respecto al núcleo urbano. Por el contrario, el infrarrojo cercano (banda 3) muestra valores, en general, más bajos. Sin embargo en la imagen TM de 1987 y en la ETM de 2001 los antiguos caminos utilizados para llegar a las parcelas 
anteriores a la concentración tienen valores más bajos en la banda 3 y 5 (rojo e infrarrojo respectivamente ) que el pueblo y las tierras desnudas, e incluso en las bandas 2 y 4 tienen valores superiores a casi todas las clases con vegetación: esto demuestra que los caminos anteriores a la concentración no provocaban impacto visual y estaban bien integrados en el paisaje; además, al ser estrechos, apenas implicaban pérdida de vegetación ni deterioro de suelo, bien protegido frente a la erosión. Esto se confirma con el análisis de los NDVI (tabla 2) donde se pueden observar mucho mejor las diferencias. El valor digital del NDVI en la imagen de 2006 es muy bajo para los caminos, lo que muestra la ausencia total de vegetación. Sin embargo en las imágenes de 1987 y 2001 no se distinguen bien los caminos ya que tiene valores más bajos (tonos oscuros) el pueblo o las formaciones de encinas (en ambas fechas) y las parcelas de cultivo en agosto de 1987, que ya habían sido recolectados o los bosques de frondosas en abril de 2001 (que aún no tenían hojas).

TABLA 1

NÚMEROS DIGITALES DE LAS BANDAS DE TM, ETM Y ASTER

\begin{tabular}{lrrrrr}
\hline $\begin{array}{c}\text { Valores } \\
\text { ND }\end{array}$ & Caminos & Frondosas & Encinas & $\begin{array}{r}\text { Cultivo } \\
\text { secano }\end{array}$ & Urbano \\
\hline TM, B1 & 93,01 & 75,20 & 85,45 & 91,96 & 115,98 \\
TM, B2 & 42,17 & 30,46 & 36,61 & 41,03 & 61,72 \\
TM, B3 & 53,00 & 27,23 & 44,13 & 53,10 & 88,78 \\
TM, B4 & 70,33 & 109,43 & 61,23 & 63,48 & 92,59 \\
TM, B5 & 144,22 & 86,08 & 102,61 & 128,93 & 184,32 \\
TM, B7 & 64,17 & 25,86 & 46,35 & 61,10 & 100,25 \\
ETM, B1 & 79,33 & 78,46 & 72,40 & 72,92 & 98,38 \\
ETM, B2 & 68,33 & 64,85 & 56,95 & 63,88 & 92,54 \\
ETM, B3 & 68,17 & 73,92 & 54,20 & 52,64 & 115,38 \\
ETM, B4 & 76,50 & 57,27 & 58,30 & 116,68 & 80,69 \\
ETM, B5 & 112,00 & 124,27 & 90,05 & 98,88 & 155,23 \\
ETM, B7 & 71,33 & 83,88 & 56,35 & 52,36 & 133,23 \\
ASTER B1 & 87,08 & 52,13 & 51,70 & 51,43 & 86,89 \\
ASTER B2 & 74,58 & 31,16 & 35,68 & 33,17 & 89,27 \\
ASTER B3 & 104,58 & 111,61 & 78,33 & 109,27 & 88,50 \\
\hline
\end{tabular}


TABLA 2

VALORES DE NDVI

\begin{tabular}{lccc}
\hline \multicolumn{1}{c}{ Uso de suelo } & 2-agosto-1987 & 10-abril-2001 & 2-junio-2006 \\
\hline Caminos & 0,31 & 0,30 & 0,07 \\
Frondosas & 0,64 & $-0,15$ & 0,61 \\
Encinas & 0,23 & 0,16 & 0,30 \\
Cultivos de secano & 0,10 & 0,44 & 0,55 \\
Urbano & $-0,04$ & $-0,09$ & 0,04 \\
\hline
\end{tabular}

El estudio mediante teledetección no sólo permite hacer un seguimiento temporal de los cambios acaecidos en los caminos construidos para la concentración sino analizar también el entorno de éstos: un entorno con gran valor ambiental caracterizado por bosques de castaños y robles en los pisos más altos y encinas en los inferiores, con una importante masa vegetal formada a lo largo de muchos años.

El precio en impacto ambiental de toda concentración parcelaria puede ser muy elevado (Gómez-Orea, D., 1994), pero si se tiene en cuenta la situación del entorno estudiado dentro de diversos espacios naturales protegidos, este impacto puede resultar muy serio. Los cerca de $80 \mathrm{~km}$ de nuevas pistas con desbroce y aplanamiento de hasta $8 \mathrm{~m}$ de anchura, han provocado directamente la desaparición de unas 60 ha de bosque maduro o en rápida recuperación, tras abandono de usos tradicionales, siguiendo una dinámica sucesional muy acelerada por la facilitación de la restauración forestal originada por los extensos matorrales en un clima mediterráneo subhúmedo a húmedo (Madrigal et al., 2007, 2008).

Sin embargo, los efectos ambientales más fuertes se están comenzando a producir con posterioridad al proceso de concentración. Son efectos indirectos y que tienden a incrementarse con el tiempo: el intenso vallado a que se están sometiendo las nuevas parcelas, en muchos casos con luces de malla rígida muy pequeñas, provoca una fragmentación e insularización del territorio (Turner, 2005) con el consiguiente impacto sobre los sistemas de dinámica metapoblacional de la, hasta ahora, rica fauna de vertebrados terrestres.

La privatización del antiguo vuelo de encinas, varias veces centenarias, que eran de uso comunal, va a propiciar la especulación y el descuido de su ma- 
nejo, aparte de la desaparición de esta curiosa y antiquísima forma de uso de la propiedad de la que van quedando muy pocos ejemplos en la Península Ibérica: privada para el suelo y comunitaria para el vuelo. Un manejo asociado a numerosas reglas y pautas culturales de raíces medievales en vías de extinción. Un patrimonio histórico y sociocultural que se debería haber protegido excluyendo estos predios de la parcelación.

Por último, el diseño rectilíneo y artificial de muchas de las vías abiertas, que no se adaptan a la morfología del terreno ni a sus cambios de nivel, ha traído consigo otros dos importantes impactos: la erosión y el arrastre de suelos de textura gruesa en pendientes a veces fuertes, y el impacto paisajístico visual, al estilo de cortafuegos, en una zona que se había librado de los mismos gracias a que sus masas forestales son naturales y autóctonas. La armonía visual sin líneas rectas que había imperado durante siglos ha sido gratuitamente destruida, ya que las alternativas eran sencillas, adaptando algunos de los recorridos más impactantes a la morfología del terreno. Este impacto visual puede tener a su vez un efecto económico indirecto importante: el abandono de los usos tradicionales de explotación del territorio, sumado a la intensa recuperación espontánea de los bosques y la belleza natural del entorno, hace que para toda la comarca de la Sierra de Francia, gran parte de sus posibilidades de explotación económica estén en el uso turístico de su belleza natural, belleza que se ve muy mermada con este tipo de actuaciones.

También la construcción de estos caminos ha afectado a los suelos ya de por sí poco espesos y bastante frágiles. Todo el término afectado por los nuevos caminos de concentración corresponde a la asociación de suelos: cambisoles y leptosoles (WRBSR, 2007) en las proximidades del pueblo y umbrisoles y cambisoles en los extremos de los caminos localizados en la sierra bajo vegetación arbórea. Con la concentración parcelaria no sólo han desaparecido muchos de los suelos sino que, en los restantes, se ha incrementado el riesgo de sufrir erosión hídrica.

\section{CONCLUSIONES}

Indudablemente la concentración parcelaria tiene numerosas ventajas para la utilización de la tierra y para un posible incremento de su valor. Pero también tiene inconvenientes que repercuten sobre todo en los diferentes elementos del ecosistema: suelos, vegetación y fauna. Por ello es necesario analizar su impacto ambiental, especialmente en áreas con gran interés biológico y paisajístico. 
Entre las técnicas más útiles para evaluar este impacto está la teledetección. La obtención del NDVI permite una mejor comparación entre el paisaje anterior y posterior a esta concentración.

En el municipio estudiado, los principales impactos en el paisaje son debidos a:

- Impacto visual en un área de alta calidad paisajística.

- Talado de bosques: desaparición de robledales y encinas.

- Problemas para el movimiento y la conservación de la fauna debido al vallado de las parcelas.

- Desaparición de suelos: umbrisoles, leptosoles y cambisoles.

- Incremento de la erosión. En el área estudiada el mayor riesgo de erosión corresponde a la erosión hídrica debido a la fuerte pendiente de muchos de los nuevos viales.

- Disminución de expectativas de explotación económica de valores naturales que se ven amenazados con este tipo de actuación, por otra parte irreversible.

Dado el carácter irreversible de estos efectos, sobre todo el de la fragmentación y el del desbroce, con la consiguiente pérdida de biodiversidad, queremos enfatizar la necesidad de replantearse las actuaciones de concentración parcelaria en áreas marginales desde el punto de vista agropecuario y de elevado interés natural, donde el balance entre los costes -económicos y ambientales- y los beneficios - sociales por actualizar y legalizar los títulos de propiedad y puntualmente económicos por mejora en la explotación de algunas parcelas- no están claros.

Recibido: 12/12/2010

Aceptado: 11/08/2011

\section{BiBLIOGRAFÍA}

Forteza, J. et al. (1987): Mapa de suelos de Castilla y León. Valladolid, CSIC-JC-L.

García, A.; Forteza, J. y Lorenzo, L. F. (1977): Mapa de suelos de Salamanca, escala 1:200.000. Salamanca, CEBAS-CSIC, 145 pp, 1 mapa.

García-Rodríguez, J. A.; Puerto, A. y Rodríguez, R. (1984): “Aplicación de un método sencillo de análisis hidrográfico al estudio ecológico del paisaje y la erosión en un área montañosa del Centro-Oeste Ibérico". Studia Oecologica, 3, pp. 301-321.

García-Rodríguez, J. A. (1991): "Las comunidades vegetales. Aspectos descriptivos y generales", en J. M. Gómez-Gutiérrez (coord.): El libro de la Dehesa Salmantina. Valladolid, Junta de Castilla y León, pp. 625-655. 
García-Rodríguez, J. A. (2004): "La interacción entre ciencia y sociedad: el caso de la biología de la conservación”, en J. M. Gómez-Heras (coord.): Tomarse en serio la naturaleza. Ética Ambiental en perspectiva multidisciplinar. Madrid, Biblioteca Nueva RS, pp. 255-287.

Gómez-Orea, D. (1994): Evaluación del impacto ambiental de la concentración parcelaria. Valladolid, Publicaciones de la Consejería de Agricultura y Ganadería, Junta de Castilla y León.

Madrigal J. et al. (2007): "Respuesta multivariante de comunidades subseriales de matorral a factores climáticos y efectos en la regeneración forestal espontánea". Ecología, 21, pp. 71-90.

Madrigal J. et al. (2008): "Exploring the influence of shrubs on herbaceous communities in a Mediterranean climatic context of two spatial scales". Plant Ecology, 195, pp. 225-234.

Rivas-Martínez, S. (1987): Memoria del mapa de series de vegetación de España. Madrid, ICONA.

Turner, M. (2005): "Landscape Ecology: what is the state of the Science?". Annual Review of Ecology, Evolution and Systematics, 36, pp. 319-344.

UNESCO (2006): "25 nuevas reservas de la biosfera se añaden a la red del programa MAB”. Comunicado de prensa 2006-130. Unescopresse

WRBSR (2007): World Reference Base for Soil Resources 2006. IUSS.ISRIC.FAO. World soil resources reports 103 .

http://earth.google.es

\section{RESUMEN}

El objetivo del trabajo es analizar el impacto que la concentración parcelaria ha provocado en el paisaje del municipio de Escurial de la Sierra situado en el sur de la provincia de Salamanca (España). Se encuadra dentro de la Reserva de la Biosfera de las Sierras de Francia y Béjar (UNESCO 2006) con valores florísticos, faunísticos y paisajísticos muy importantes. Para ver los efectos de la concentración se comparan imágenes de satélite anteriores y posteriores a ella. La creación de pistas con desbroce y aplanamiento de hasta $8 \mathrm{~m}$ de anchura ha provocado la desaparición de numerosas hectáreas de bosque maduro o en recuperación. El vallado al que se están sometiendo las nuevas parcelas provoca una fragmentación e insularización del territorio con el consiguiente impacto sobre los sistemas de dinámica metapoblacional de la rica fauna de vertebrados terrestres.

PALAbras Clave: concentración parcelaria; impacto ambiental; paisaje; teledetección.

\section{AbSTRact}

The objective of this paper is to analyse the impacts caused by the concentration of land holdings on the landscape of Escurial de la Sierra, a village located in the south of the province of Salamanca (Spain). This village is part of the Biosphere Reserve of 
the Francia and Bejar mountain ranges (UNESCO 2006) due to the importance of its vegetation/flora, fauna and landscape. In order to observe the effect of the concentrations, several satellite images taken before and after the concentration process have been compared. The creation of 8 metre wide tracks by cutting trees and flattening the land has caused the disappearance of many hectares of forests which were either mature or in a process of regeneration. The fencing of the new parcels of land is causing the fragmentation and insularity of the land, resulting in a major impact on the metapoblational dynamics of the rich invertebrate land fauna.

KEY WORDS: concentration of land holding; environnmental impact; landscape; remote sensing.

\section{RÉSUMÉ}

L'objectif de l'étude est d'analyser l'impact que la concentration parcellerait a provoqué dans le paysage de la municipalité d'Escurial de la Sierra situé dans le sud de la province de Salamanque (l'Espagne). Il est encadré à l'intérieur de la Réserve de la Biosphère des "Sierra de la France et de Béjar" (UNESCO 2006) avec valeurs floristiques, faunistiques et du paysage très importants. Pour voir les effets de la concentration on compare des images de satellite antérieures et postérieures à elle. La création de pistes avec débroussaille et un aplanissement de jusqu'à $8 \mathrm{~m}$ de largeur a provoqué la disparition de nombreux hectares de forêt mature ou dans une récupération. La clôture à laquelle les nouvelles parcelles se soumettent provoque une fragmentation et insularization du territoire avec l'impact résultant sur les systèmes de dynamique metapoblational de la faune riche de vertébrés terrestres.

MotS CLÈS: concentration parcellerait; impact sur l'environnement: paysage; télédétection. 